\title{
DBL Oncoprotein
}

National Cancer Institute

\section{Source}

National Cancer Institute. DBL Oncoprotein. NCI Thesaurus. Code C17316.

Human MCF2 Oncoprotein is a product of a mutated variant (Oncogene MCF2) of widely expressed MCF2 Gene, which encodes 4 alternative variants of 66-kDa MCF2 (DBL) p66 Protein, a cytoplasmic and membrane phosphoserine guanine nucleotide exchange factor that modulates the activity of small RHO GT Pases by promoting conversion from GDP- to GT P-bound form. p66 contains a CRAL-TRIO domain, a DH domain, a PH domain and a spectrin repeat; the DH domain catalyzes GDP-GTP exchange. Five-prime recombinations of MCF2 delete $\mathrm{N}$-terminal codons, producing activated oncogenic variant; the upstream replacing sequence, URS, is derived from D15S93 at 15q15-q23. MCF2 Oncoprotein disrupts normal cell function. 